\title{
Web-Based Language Learning (WBLL) for Enhancing L2 Speaking Performance: A Review
}

\author{
Ngo Cong-Lem*
}

Department of Applied Foreign Languages, National Taiwan University of Science and Technology, 43, Section 4, Keelung Road, Da'an District, Taipei City 10607, Taiwan

Corresponding Author: Ngo Cong-Lem, E-mail: ngoconglem@gmail.com

\section{ARTICLE INFO}

Article history

Received: March 11, 2018

Accepted: June 27, 2018

Published: August 31, 2018

Volume: 9 Issue: 4

Advance access: July 2018

Conflicts of interest: None

Funding: None

\section{Key words:}

Web-Based language learning,

L2 Speaking,

Web 2.0 tools,

Blogging,

Communication Tools, Learning Management System, Educational Technology

\begin{abstract}
The advent of Web 2.0 technology has afforded language educators more useful technology for English as a foreign language (EFL) teaching. This article reviewed 31 empirical studies investigating the employment of web-based technology to enhance EFL learners' speaking performance. The findings indicated that overall, web-based language learning (WBLL) could be classified into five major groups: general websites providing linguistic inputs, blogging platforms, communication tools, project-based learning tools and learning management systems. While the available linguistic input online, e.g. web articles and videos, helped to enhance learners' linguistic and background knowledge, other communication/chat tools facilitated peer interactions and collaborative learning. Audio- and video-based blogging provided convenient platforms for learners to practice their speaking through sharing their personal experiences. Moreover, Web 2.0 technology as a learning management system helped to create a ubiquitous learning environment, where L2 learners could engage in the language learning process without time and space constraints. WBLL was also found to reduce L2 learners' learning anxiety while making them become more active, motivated language learners. In addition, the role of language instructor in web-based technology implementation was also found to be crucial, e.g. monitoring L2 learners' learning progress and providing feedback. Further research, however, is warranted to address existing methodological drawbacks of previous studies by recruiting larger sample size, conducting long-term research and controlling for confounding factors, e.g. prior L2 speaking ability and technology usage experience.
\end{abstract}

\section{INTRODUCTION}

Nowadays, technology plays an increasingly important role in language classrooms and it is commonplace for teachers, to a certain extent, to apply technology-assisted language teaching (Sun \& Yang, 2015). The advent of the Internet has allowed people around the world to stay connected, sharing and contributing to the world knowledge. If in the age of web 1.0 technology, people surf on the internet mainly as readers, today, Web 2.0 enables the Internet users to be part of the world knowledge contributors (Faizi, 2018). Instead of passively reading web content as in the former, online readers today can comment, provide feedback and contribute their knowledge, e.g. blogging. Web 2.0 also revolutionizes the way people contact and communicate with each (Qarajeh \& Abdolmanafi-Rokni, 2015). For instance, instead of reaching friends via their phone or email, nowadays people can keep in touch by making friends on Facebook, a popular social networking site, and message or call each other via this free platform.

The rapid development of information technology, particularly web 2.0 , has merited language education in a sig- nificant and innovative manner (Luo, 2013). In recent years, Web-Based Language Learning (WBLL) has been emerging as a popular term in language education field. There has been an increasing number of studies that address the employment of web-based tools in language classrooms. Web-based technology has currently enabled language instructors to extend their teaching practice beyond the physical constraint of their language classroom (Lai \& Gu, 2011). For example, in blended learning, besides attending face-to-face traditional language class, learners also engage in online activities out of school. Language learning has become ubiquitous, i.e. EFL learners can practice their English skills without time and space constraints. They have more opportunities to learn and practice the target language through collaborative learning with their peers or creating their own projects (Ghoneim \& Elghotmy, 2016). WBLL can assist the language acquisition process in that it allows learners to interact with each other as well as gradually construct their own knowledge (Lin, Shie \& Holmes, 2017). In Vygotsky's sociocultural theory (1978), social interaction with other people was considered key to human learning. The theory discusses the importance of "zone of proximal develop- 
ment", i.e. the potential higher achievement a person can accomplish with assistance from more able individuals. By the same token, the interaction hypothesis by Long (1996) stated that an individual learned a language through social interactions through which better speakers assisted the lower-ability ones. During the meaning-negotiation process, interlocutors can pick up new linguistic information through feedback and comprehensible input from their interlocutors (Long, 1996). The implementation of web-based tools is, hence, to create more opportunities for the foregoing meaningful interactions among language learners and with their instructor as well.

Regarding English learning as a foreign language (EFL), of the four language skills, speaking tends to be the hardest skill to acquire, particularly provoking learners' anxiety (Sun \& Yang, 2015; Ur, 1996; Zhang, 2009). Despite extensive learning experience, EFL learners oftentimes struggle to communicate in the foreign language (Al Hosni, 2014). One of the common reasons identified in previous literature is that learners lack the opportunities to practice their speaking skill (Baniabdelrahman, 2013; Sun \& Yang, 2015). For example, in Asian EFL context, due to the examination-oriented nature of language training, language lessons are likely to focus on the grammatical and lexical aspects of the target language, rather than teaching speaking and listening skills (Dailey, 2010). Also, since it is the learners' foreign language, they normally do not have many opportunities to communicate with the native speakers. Culture-related factors, such as power distance between teacher and students, i.e. learners are supposed to obey their teachers, also discourage students to speak up in class (Dailey, 2010; Kasuya, 2008). They are shy and afraid of making mistakes, which may lead to humiliation from their friends or will make them lose "face" (Wei, 2014).

To address the above-mentioned challenges, web-based technology has been increasingly implemented in language classrooms to enhance learners' L2 oral competence. While Web-Based Language Learning (WBLL) has gained its position in the field of language education, support for WBLL practice mainly come from arguments based on a theoretical basis, rather than based on empirical evidence (Luo, 2013). Although there have been a few studies reviewing Web 2.0 technology, a majority of previous reviews were conducted more than a decade ago and their findings may not reflect the development of today's educational technology. Also, the author found no review article that focuses specifically on how WBLL impacts learners' L2 oral performance. As educational technology is developing rapidly, more up-to-date review is needed to inform WBLL future research directions as well as pedagogical practice.

The current paper purports to review empirical studies that utilized WBLL in foreign language education. Firstly, this review is expected to inform relevant stakeholders of the available Web 2.0 tools for developing L2 speaking proficiency and how the web-based technology have been integrated into foreign language classrooms. Moreover, this review also aims to inform researchers, particularly novice professionals, of the available research topics and research designs for conducting WBLL empirical studies. Additionally, pedagogical implications for teaching L2 speaking skill are discussed in the light of previous findings. Suggestions for future research in WBLL area will be put forward with the intention to address methodological drawbacks in previous studies.

\section{METHODOLOGY}

In the search for the literature to be reviewed in this study, various journal and paper search engines were utilized, i.e. Google Scholar, Google, Eric, Scopus, and Web of Science. A variety of searching keywords were used, for example, "Web-based language learning", "L2 oral performance", "Internet-based language teaching", "Web 2.0 tools", and "EFL students' speaking skill". Several criteria were set for the studies to be included in this literature review:

- Empirical studies, i.e. the researchers apply the webbased tools in real language classrooms, not papers that only suggest ideas or discuss teaching methods in general

- Web-based tools and resources, not desktop computer software/applications. This means that the study must utilize materials or technologies that are available online without having to download it and install in their computer to use.

- $\quad$ Language-education papers, i.e. the purpose of the research studies is to enhance L2 oral skills/communication skills of the language learners, not studies using web-based tools to teach knowledge in other fields.

- $\quad$ Focusing on L2 speaking skill

- $\quad$ Published from 2003 - 2018. This is to keep this review updated with more modern technology, thus being more meaningful and relevant to readers.

\section{FINDINGS}

After the extensive and intensive journal search, 31 papers that met the selection criteria mentioned above were chosen for the next review process. Although most of the web-based tools are multi-functional, i.e. they can be used for different purposes, and the obtained papers were classified into five categories for the sake of clearer demonstrations of the webbased technology (see Table 1). However, it must be stressed that the classification is relatively flexible, and a certain technology can be classified into more than one group.

As one of the purposes of this review paper is also to provide readers with the information on WBLL research design, how the researchers designed their empirical studies will also be reported, rather than simply stating the results (e.g. Luo, 2013; Yusof \& Saadon, 2012).

\section{Learning Resources}

The Internet has become an integral part of our daily life. In language education, it provides unparalleled linguistic input resources that can be utilized in teaching and learning a foreign language. Previous researchers have attempted to create/utilize the already available websites as a rich source of linguistic input to enhance their learners' L2 speaking ability.

Chiu, Liou and Yeh (2007) developed a website equipped with automatic speech recognition technology that taught 
Table 1. A Category for Web-based Language learning tools

\begin{tabular}{|c|c|c|}
\hline & WBLL groups & Educational use \\
\hline 1 & Learning resource & $\begin{array}{l}\text { General websites providing language learners with linguistic input materials, e.g., newspapers } \\
\text { and video-streaming websites. }\end{array}$ \\
\hline 2 & Blog & $\begin{array}{l}\text { Web-based platforms for language learners to practice their language skill by posting written } \\
\text { text, audios or videos. }\end{array}$ \\
\hline 3 & Communication tool & $\begin{array}{l}\text { Online platforms for students to communicate via text, audio or multimodal } \\
\text { video-conferencing. }\end{array}$ \\
\hline 4 & Project-Based learning tool & $\begin{array}{l}\text { Websites with technology allowing students to create their learning projects, such as digital } \\
\text { story videos or presentations. }\end{array}$ \\
\hline 5 & Learning management system & $\begin{array}{l}\text { Web-based systems for online learning management, e.g., storing lesson materials and sending } \\
\text { out or receiving learners' assignments. }\end{array}$ \\
\hline
\end{tabular}

EFL learners in Taiwan the six speech acts in English, i.e. greeting, saying goodbye, request, complaint, apology, and compliment. The web-based environment guided the students through different situational conversations and required them to record their oral responses based on the given contexts. The participants practiced with the technology in class and at home during a course of six weeks. They were then administered a self-developed Discourse Completion Test. The findings showed that while students' appropriateness of speech act use improved, the comprehensibility level, i.e. how easy it is to understand the speech act utterances, did not. It seems that the study could only partially address its purpose in enhancing the learners' communication ability in using speech acts. In this case, the researchers developed themselves the website to provide linguistic input.

In other studies, educators employ the real-life websites already available on the Internet for their language teaching purpose. For example, TED Talks is one of the most popular online websites for learning about presentation skills. Li, Gao and Zhang (2016) employed the TED videos in their public speaking course. In their study, the authors elaborated on the noteworthy reasons motivating them to choose TED Talks videos. First, TED videos featured a variety of topics that suited the language learners' individual interests. Also, the fact that presenters came from different countries around the world could help to familiarize their learners with different English accents. Students had the flexibility to watch the videos repeatedly, learn new vocabulary and acquire effective presentation techniques. Speakers in TED videos commonly possessed great presentations skills, for example, using body language, which learners could imitate and learn. Participants in their study were 150 EFL engineer-major students. During the treatment period, learners were requested to watch TED videos, take notes and present their own speeches in class. They also self-evaluated their own performance as well as receiving feedback from their classmates. Analyses from self-report questionnaires showed that students believed they picked up more linguistic information and enhanced their speaking proficiency. Specifically, the students reported an increased amount of speaking practice and became more confident in public speaking. The knowledge presented in the TED videos also benefitted the students' knowledge and critical thinking skill. However, it should be emphasized that TED Talks is only one represen- tative among many other educational websites that can be utilized to enhance learners' presentation skill.

Peyghambarian, Ashraf and Fatemi (2014) encouraged their Iranian EFL learners to access a website named "GoEnglish.Me" to learn and practice language skills. The online website contained different linguistic resources, e.g. reading and listening materials. The study had an experimental design with a control group whose participants only studied in regular classes without using the online resources. Consistent with many previous studies in web-based language learning, the experimental group students outperformed control group counterparts in speaking ability as indicated in their speaking posttest.

\section{Blogging}

When mentioning "blog", people may think of it as an online website to share personal writing. Nevertheless, webbased technology now enables its users to create multimodal blog posts, embedded with text, pictures, audios and videos. Besides, commenting and interacting are also learners' popular behaviors as Web 2.0 bloggers. Secondary Taiwanese children in Lin, Shie and Holmes' (2017) were instructed to share their local cultural activities with their British children partners via an online blog platform. The Taiwanese participants demonstrated in their post-treatment survey that interacting with other foreign peers on the blog helped to improve their communicative competence as well as general English proficiency. The project, according to the researchers in the study, assisted the development of both foreign language skill and cultural knowledge through meaningful and interesting interactions.

Educators commonly preferred audio-blogging and video-blogging, i.e. sharing personal experience/knowledge through recording audios or videos respectively, to enhance language learners' L2 oral performance.

\section{Audio blogging}

In the pursuit of creating more speaking practice opportunities for language learners, researchers have attempted to implement different audio-recording technologies in language teaching practice. Appel and Borges (2012) conducted a study employing a web-based application named LANG- 
blog, developed by the researchers' institution, to facilitate speaking practice for distance learners. As part of the online LANGblog platform, an audio-blogging forum was created for the learners to share their own audios as well as listening to others'. The participants predominantly supported the employment of the web-based audio-blogging platform as they believed it enhanced their oral communication skills. Likewise, keeping oral diaries, though simple, has also been found to benefit language learners' speaking competence. Baniabdelrahman (2013) asked Saudi Arabian undergraduate students to audio-record their daily life events and then upload the files to an online blog. The students were also required to listen and comment on their peers' audio diaries. Another group of students served as a control group and studied in regular classes without practicing diary recording. Students' speaking ability was measured in pre- and posttest. It was found that EFL learners who joined the shared online diaries significantly outperformed their peers in the control group. The study concluded with the support for the utilization of oral diaries in teaching English speaking skill.

Another worth-mentioning research is Huang's (2015a) in which the author required his participants to integrate both reading and speaking skill into audio-blogging practice. His study purported to develop EFL students' oral proficiency and to examine their perception of audio-blogging as an educational tool. Participants, 74 freshmen students in Taiwan, were instructed to follow a four-phase procedure in carrying out the study activities. They first needed to read online information to acquire necessary background knowledge about a topic of their interest. Then, they were asked to plan and organize a speech before audio-recording it in the third stage. The last phase was to share their audios to a web-based blog. Commenting on other students' work was also expected. The participants' attitude towards the blogging experience was inquired through a perception questionnaire. The EFL learners pointed out the advantages of the web-based activities in regard to enhancing their linguistic abilities, background knowledge and relationships with their friends. Huang's study is one of the first, among relatively few studies, to integrate reading and speaking skill in learning with webbased resources.

More recently, Hsu (2016) utilized an online platform to provide her Taiwanese EFL students with extra-curricular speaking practice. The students recorded their speaking about a topic related to their course materials and uploaded it to a blog. They also listened to their peers' audios and provided feedback. The researcher then analyzed the participants' audios in the first two weeks and in the last two weeks to compare their speaking content in terms of complexity, accuracy and fluency. While the mean length of speaking audios was extended, neither the accuracy nor fluency was significantly improved. This implies quantity of speaking practice might not suffice for learners to improve their speaking fluency and accuracy. Language instructors should further provide corrective feedback to enhance the quality of their language learners' speaking practice.

\section{Video blogging}

As mentioned above, besides blogging with audios, another option is to blog with videos. In Shih' study (2010), a group of Taiwanese EFL learners studying English Public Speaking course, were coached to create English videos for their online blog. When receiving feedback from the teacher, they needed to revise their videos and re-upload the newer version. The integration of video-based blogging into the English classroom was reported to enhance the students' learning effectiveness as well as learning satisfaction. The feature of the web-based blog such as free access, easy revision, and interesting materials were highly appreciated by the learners in the study.

YouTube can be considered as one of the most popular Web 2.0 platform for carrying out video blogging or so-called vlogging. For instance, Combe and Codreanu (2016) conducted a comprehensive analysis of the potential influence of vlog practice on an individual's verbal competence and intercultural knowledge. They analyzed an American vlogger who shared his French learning experience on YouTube. The researchers indicated that video-based blogging practice afforded the vlogger opportunities for augmenting digital literacy skills, L2 speaking skill, and cultural exchanges with global audience. The process of recording, editing and publishing a video helped learners to enhance their digital competence (Combe \& Codreanu, 2016). Through sharing cultural knowledge on YouTube, the American vlogger received comments from viewers around the world, sparkling enthusiastic intercultural exchanges. The vlogging practice led to peer collaborative learning, constructing intercultural knowledge together.

In Hung and Huang's study (2015), the researchers instructed 36 EFL learners in Taiwan to create three-minute presentation videos and uploaded them to an online video-blogging platform for a duration of 18 consecutive weeks. While improvement in students' presentation skills was significantly enhanced through the blogging practice, anxiety was also reported by the participants. The English learners experienced learning anxiety due to the fact their presentation videos were available to the public world. This finding certainly suggests a privacy concern in the video-blogging practice that language instructors should take into consideration in order not to heighten the EFL learners' learning anxiety.

\section{Communication Tools}

Web-based technology can provide a convenient platform to increase language learners' interaction opportunities. Through meaningful interactions, learners can learn from each other and practice the linguistic knowledge they have learned in class. Previous WBLL studies have utilized web chat applications to facilitate learners' interaction in the target language. Web 2.0 enables EFL learners to communicate with other peers in multimodal format, i.e. using text, audios, videos or a combination of the foregoing.

Skykes (2005) investigated the effect of chat modes (i.e. text-based or audio-based chat) on language learners' 
speaking development. An intervention was conducted to teach participants different types of speech acts in English. Drawing on experimental research design, the participants, Spanish-learning students, were split into three groups: text chat, audio chat and control group - without chat activities. The learners first watched videos modeling how speech acts were demonstrated in real-life situations. They then discussed the video content and practiced the dialogues via different chat modes, i.e. text-based or audio-based chat. The findings revealed that synchronous chatting activities increased students' competence in performing speech acts compared to the control group, with text-based chat condition yielding the most favorable results. The researchers ascribed the result that text-based chat was superior to other chat modes to the reason that written chat allowed learners more time to process and produce the speech acts, thus better facilitating the speech-act acquisition. By the same token, Satar and Ozdener (2008) also examined how chat modality, i.e. text-based and voice-based communication, influenced EFL learners' speaking performance and anxiety. Participants were divided into three groups: control group, textbased and audio-based chat group. Students were assigned different tasks to accomplish through online chat sessions, each lasting for approximately 45 minutes. After the fourweek treatment, the results showed that although both of the chat-conditioned groups enhanced their L2 oral skill, only the text-based chat modality helped to reduce the students' language learning anxiety.

Wang and Chen (2007) carried out a study probing into the effectiveness of online real-time interaction between the instructor and language learners in a distance education context. The web-based system utilized for the study purpose was reported to enable its users to chat, collaborate on the same virtual board and video-call each other. A two-hour live lesson was conducted by the language instructor every week and for ten consecutive weeks in total. Participants were seven adult learners who enrolled in the distance online course to learn Chinese. During the online class, learners were required to complete various tasks, such as role-playing, games, and practicing dialogues. They could chat and discuss with other learners through written texts or oral talks. The participants in the study overall had a positive attitude towards the learning experience assisted by the web-based system. However, the distance learners also reported encountering a number of technical difficulties and suggested technology-training sessions being conducted before the actual implementation of the online chatting practice.

The above-mentioned studies investigate the overall efficacy of different chat modes in assisting L2 oral practice. The following section will report on studies that specifically employed a certain type of chat mode, i.e. text, audio or video chat.

\section{Text chat}

Interaction via chatting on a written-text basis has been found to positively impact oral skill. Indeed, Blake (2009) examined how online and face-to-face discussion assisted language learners' L2 speaking skill. Thirty-four ESL students participated in the study and were split into three groups based on interaction methods. The first group discussed vocabulary and content of the lesson face to face, whereas the second group utilized WebCT Vista, an online chat platform, to discuss with their peers. The third group served as a control group whose participants studied the lesson individually. Participants' speaking improvements were measured on several criteria: speaking rate, phonation time ratio (i.e. pause-excluded speaking time/total time speaking), articulation rate (number of spoken syllables/pause-excluded speaking time), mean length of run (total number of syllables/total number of speech segments) and average length of pause (total length of pauses/total number of pauses). Analysis of the data revealed that students participated in the online text-based chat significantly achieved higher scores on phonation time and mean length compared to the other two counterparts. This finding suggested that learners in the web-based chat group could speak more and with longer speech segments in the posttest. While this result is encouraging, the remained three fluency features, i.e. speaking rate, articulation rate and average length of pause, were not found to be statistically significant.

Razagifard (2013) also employed a written-chat tool to facilitate the EFL speaking skill development of Iranian learners. The study adopted an experimental design, splitting 63 participants into experimental and control groups. The former underwent through five sessions, practicing speaking skill with different communicative tasks, e.g. jigsaw, problem-solving, and decision making. During the process of carrying out the communication activities, the participants were allowed to utilize $W e b C T$, a web-based chat tool, to discuss and collaborate together. Learners in the treatment group were able to improve different aspects of fluency such as faster speech rate and speaking more words.

\section{Audio chat}

Abrams (2003) implemented a web-based audio chat platform to assist his college students' speaking skill. However, his study particularly aimed to examine how synchronous and asynchronous audio chat affected learners' L2 speaking ability. The learners' oral performance was assessed on different aspects involving the quantity of communicative units, lexical richness, lexical density and syntactic complexity. The language learners were assigned articles to read before their online oral discussion. Participants were divided into three groups: synchronous chat group, asynchronous group and control group. As their names indicated, the synchronous carried out voice-chat activity in real time, whereas the asynchronous participants could respond to their peers' oral message later during the week. The control group studied in traditional language classes where speaking skill was not emphasized. The results indicated that while the students' speaking was enhanced in terms of speaking amount, no significant gains in lexical and syntactic features were recorded. By the same token, Baradaran and Khalili (2009) recruited 52 university students to examine the advantage of online audio chat. While control group students practiced English speaking in class, the treatment group talked to each 
other via a web-based chat environment at their home. The treatment prolonged for 20 sessions before participants taking their speaking posttest. Although the authors claimed that there was a significant difference between the students' speaking proficiency, the actual difference was rather small, with the p-value being at 0.046 .

\section{Video chat/Conferencing}

Turkish EFL learners in Candarli and Yuksel's (2012) attended live video-conferencing sessions delivered by native English speakers about a lesson-related topic. Post-surveys revealed a positive attitude of the participants towards the web-based conferencing experience. They believed that the live session helped them to acquire more knowledge and felt more relaxed. Technical difficulties and the content of the video-based live lesson were found to be factors that influenced students' perceptions. Interestingly, despite positive feedback for the video-conferencing technology at the beginning, students' attitude towards it was slightly negative after participating in the live sessions and almost half of the participants refused another similar opportunity. The researchers expounded the negative results on technical difficulties and the potentially less interesting topic presented in the live sessions.

Another tool for online video-based communication is Google Hangout. The web-based tool was utilized in Saito and Akiyama's study (2017). Thirty Japanese EFL students were divided into experimental and control groups. Students in the former group were instructed to video-chat with native English speakers on a weekly basis for a course of 12 weeks. The native English interlocutors were trained to provide effective, interactional feedback to assist the EFL learners' speaking skill. On the other hand, the control group learners were assigned vocabulary and grammar exercises. It was indicated in the study findings that the participants improved different L2 speaking aspects involving speaking fluency, comprehensibility, and lexical and grammatical aspects. Surprisingly, the participants' pronunciation and accentedness were, nonetheless, not improved. The authors ascribed the nonsignificant result to the reason that the length of the treatment was too short for a significant change in the learners' pronunciation to occur.

\section{Project-based Language Teaching Tools}

With the facilitation of web-based technology, project-based language teaching can be implemented more efficiently. Sun and Yang (2015) asked fourteen EFL university students to create presentation videos about their university and city, e.g. sightseeing spots, and uploaded them on Facebook and YouTube. The project was reported to help the participants to enhance their public speaking skill, confidence, and learning strategies. The researchers concluded that Web 2.0 technology held great potential for language education, particularly due to its wide range of target audience and the affordance of convenience for communication purposes. Huang (2015b) examined how video projects could enhance students' motivation and language skills. Beside face-to-face learning in class, the study participants, 43 Taiwanese EFL learners, were also assigned outside-class tasks, which involved reading on the Internet, voice-blogging, and creating two-minute multimodal videos. The students were allowed to choose their own topic for the video projects and utilize pictures and audios to illustrate their ideas. The findings demonstrated that the project-based teaching approach significantly increased the participants' TOEIC scores in the posttest as well as enhancing their learning motivation.

In Hwang et al's (2016), Taiwanese sixth-graders were provided with pictures from which they were coached to create digital story videos. A web-based platform was constructed by the researchers, equipped with various useful functions to create a multimodal digital story. In addition to utilizing the web system to add text, picture, and animation to their project, the children were also expected to add their own voice to narrate the story. It was found that the EFL learners significantly improved their speaking ability in comparison with their counterparts in the control group. Moreover, the use of animations to create videos was significantly associated with the participants' learning achievement. However, the researchers' interpretation of this correlation as a causal relationship, i.e. engagement in creating the story animations led to improvement in learning achievement, necessitates further investigation. Indeed, in a follow-up analysis, the researcher failed to confirm the animation-designing activities as a predictor of the participants' learning achievement. Furthermore, it is also noteworthy from the study findings that individual work, but not pair work, was a predictor of the students' speaking accomplishments. Unwillingness to cooperate and misbehaviors from their partners were reported as the main causes.

VoiceThread is an online website that allows its users to design multimodal presentation. Comments on others' work can also be made in a text, audio or video format. Ghoneim and Elghmotmy (2016) used the foregoing web-based tool in their study to enhance pre-service English teachers' L2 communication skill. Participants had the flexibility to practice speaking on the platform without time and space constraints. The online discussions were initiated either by the teacher or the participants. Regarding the findings, participants' overall speaking ability improved in both accuracy and fluency criteria. In the same vein, Dugartsyrenova and Sardegna (2017) also employed VoiceThread in their language classroom. Eight undergraduate students studying Russian as a foreign language accessed the class materials on VoiceThread. They were instructed to practice speaking skill by recording their own speech, listening to other audios and commenting on others' work. The findings revealed that the participants held a positive attitude towards the web-based platform, stating that it enhanced their oral proficiency in regard to vocabulary, pronunciation, accuracy, and fluency. They also appreciated the oral feedback from their language instructor. The learners also indicated that they preferred uploading their speaking audios to speaking up in class. Finally, although praising the use of technology, the students also mentioned the necessity of face-to-face interactions for their language learning process. 


\section{Learning Management System}

Web 2.0 technology enables language educators to transform language teaching practice. In recent years, blended learning and flipped classroom have been promoted as two innovative teaching methods for language teachers. While the former integrates technology partly into language classroom, the latter completely reverses the order of traditional language class. In flipped teaching method, teaching materials are made available online for students to study outside classroom before coming to the class. During their face-toface meeting in class, instead of traditionally listening to the teacher lecturing the knowledge, learners practice what they learn at home via discussions and projects. Web 2.0 offers learning management systems that educators can utilize to manage and organize learning materials as well as online activities. In the following section, research studies employing Web 2.0 technology in blended and flipped teaching class to enhance learners' $\mathrm{L} 2$ oral performance will be reviewed.

Dias and Pimenta (2015) adopted a blended-learning approach to enhance pre-service English teachers' communication ability. Moodle was employed as the learning management system to host the class activities. Regarding the online components of the course, learners were instructed to utilize a variety of web-based applications, for example, voice mail, Voki - a virtual space for creating virtual avatars, audio recorder, and online dictionaries. Other Internet resources were also exploited, e.g. YouTube videos, TED Talks videos, and movie trailers. The authors observed that their participants could apply the available web-based tools and resources effectively for their language learning process, thus improving their L2 speaking competence. Likewise, Iranian EFL learners in the treatment group in Qarajeh and Abdolmanafi-Rokni's (2015) were requested to join an online social networking group operationalized on the Yahoo.com website. Participants took their speaking posttest after the three-month treatment. The results demonstrated a significant improvement in speaking performance for learners in the experimental group. However, no report was made for whether the control group students had their speaking skill enhanced.

Malaysian ESL learners ( $\mathrm{N}=75)$ in Tazijan, Baharom and Shaari's (2016) participated in a five-week flipped-teaching program purporting to improve the students' presentation skills and L2 oral competence. The lesson materials were uploaded to Facebook and Twitter, the two Web 2.0 platforms employed as language learning manage systems for the course. Available web resources, i.e. YouTube videos and TED Talks videos, were utilized as linguistic materials for the lessons. Students were asked to review and study the materials before coming to the class. Regarding in-class activities, discussions were first conducted online via the social media sites, followed by practicing speaking. For the course evaluation, participants were required to perform oral presentations as well as group discussions. The web-based language teaching was found to promote the learners' active learning and engagement, thus improving their verbal communication skills. The researchers appreciated the educational affordance of Web 2.0 technology, providing students with flexibility in learning (i.e. being able to prepare/study the lesson materials outside class) and more opportunities to practice the target language in class. The findings also revealed that the learners were particularly excited about the employment of social networking site for class discussions.

In Li and Suwanthep's research (2017), 46 EFL learners in Thailand were recruited for an experimental group and another 48 students for a control group. The experimental group was taught vocabulary and grammar via online lessons and spent their class time practicing constructive role-playing speaking. In contrast, the control group practiced their speaking through question-answer drill activities. The web-based tool utilized in the study was EDpuzzle, an online learning management system. After a twelve-week treatment, positive results were recorded in favor of the experimental group who significantly gained higher speaking achievement in the posttest compared to the control group students. To gain further insights into the flipped classroom practice, the researchers conducted surveys and interviews. Overall, the Thai EFL learners expressed a positive attitude towards the flipped-class experience, stating that it allowed them to study without time and space constraints and afforded more speaking opportunities in class. However, one of the drawbacks identified with the teaching method was that learners could not ask immediate questions when they reviewed the lesson materials.

Köroğlu and Çakır (2017) developed a blended-learning syllabus integrating an online web-based technology to teach communication skills to pre-service English language teachers. A learning management system, Edmodo, was employed to host the online component of the course. After eight weeks, their participants' speaking skill was found to improve in all five criteria, i.e. pronunciation, speaking fluency, coherence, vocabulary and grammatical accuracy. Another study by Vasquez and Arciniegas (2017) employed WebQuest for their language class. The participants, EFL learners, accessed the WebQuest site for class instructions. The web platform provided participants with instructions about the tasks and links to a variety of online resources to accomplish the communicative assignments. Flexibility in time and space was reported as an attractive feature of the web-based course. For instance, participants in the study could start collecting materials for the next class at home after they read the instruction on the website. Also, online web-based tools such as dictionary made it convenient for the learners to check word meaning. By reading and watching online L2 resources, language learning can enhance their speaking communicative competence and cultural knowledge (Vasquez \& Arciniegas, 2017).

\section{DISCUSSION}

In the result section, five major types of Web 2.0 tools for L2 oral training were identified: general websites - providing linguistic resources, blogging platforms, communication tools, project-based learning tools and learning management systems. Aims, research methods and findings of the reviewed studies were discussed. In this section of the review, implications and limitations of previous WBLL research will be elaborated. 
WBLL afforded language learners with unlimited online resources for language learning purposes. Given the plentiful sources of linguistic input on the Internet, language learners should make use of these L2 resources (e.g. web articles, TED Talks, and YouTube videos) to acquire linguistic knowledge while improving their background knowledge. It is noteworthy in previous research that participants were oftentimes allowed to choose their own reading topic, thus being motivated in web-based reading (Huang, 2015a). Additionally, the learners were ensured to possess some background knowledge about the task which they were going to be assigned (e.g. Tazijan, Baharom \& Shaari, 2016; Vasquez \& Arciniegas, 2017). Pedagogically, it is thus essential for language instructors to link between input and output practice. This means learners should be equipped with not only linguistic knowledge but also background knowledge before being able to communicate effectively in the target language.

Audio-based and video-based blogging have now become popular in training L2 oral competence. The online blogging sites provide learners with virtual environment to practice L2 speaking through sharing audios/videos about their personal experiences. This helps to create an online community where students can collaborate and learn from each other through peer feedback (e.g. Baniabdelrahman, 2013; Dugartsyrenova \& Sardegna, 2017; Ghoneim \& Elghmotmy, 2016). Through blogging, besides improving L2 oral proficiency, learners can also acquire socio-cultural knowledge and skills as well as building relationships with their classmates (Baniabdelrahman, 2013; Combe \& Codreanu, 2016; Lin, Shie \& Holmes, 2017). Notwithstanding asking students to share their personal speaking audios/videos with their friends may encourage their active learning and engagement (Tazijan, Baharom \& Shaari, 2016), making their oral presentations available to the public audience, i.e. to the outside world, can provoke more severe learning anxiety among EFL learners (Hung \& Huang, 2015). Educators are, therefore, advised to take into consideration whether their students are ready to share their work to the world audience on the Internet.

Online chatting tools can be utilized to create a student-oriented learning environment where more opportunities for target language practice are available to L2 learners. Learners' collaborative language learning can also be facilitated with web-based communication platforms. Indeed, during chatting sessions, learners can interact, exchange information and cooperate to solve language tasks (Satar \& Ozdener, 2008; Razagifard, 2013; Wang \& Chen, 2007). Through peer interactions, skills/knowledge students have learned in class can be reinforced; students can also learn new lexical and grammatical features from interactions with better speakers as well. It should be, however, pointed out that the quantity of L2 speaking practice does not always turn into quality improvements (e.g. Abram, 2003; Hsu, 2016; Saito \& Akiyama, 2017). This is when the role of language instructor comes into play. Instead of solely depending on web-based technology, language professionals should actively monitor their learners' speaking development progress and provide timely, necessary feedback to ensure the language learners can improve their L2 oral competence regarding both fluency and accuracy aspects. Students may develop negative attitude towards a certain technology if the lesson content is not well-prepared or interesting (e.g. Candarli \& Yuksel, 2012).

Web 2.0 also revolutionized language education by making the learning process become ubiquitous, e.g. in blended learning and flipped classroom approach. Educators can employ web-based learning management system (e.g. Moodle and Edmodo) to make lesson materials available online. Learners can then study the lessons outside classroom at their convenience and spend more class time accomplishing L2 speaking activities (Li \& Suwanthep, 2017; Tazijan, Baharom \& Shaari, 2016). More speaking opportunities are particularly essential for language learners in EFL context, where opportunities for practicing the target language are much needed. Regarding flipped classroom approach, language educators should also take further steps to provide support for learners who may encounter difficulties in autonomously studying the lesson materials at home (e.g. Li \& Suwanthep, 2017).

Besides encouraging findings, several limitations in previous WBLL studies should be addressed in future research. First, the number of participants tend to be limited, which may threaten the reliability of previous research findings and their generalizability. Secondly, the duration of implementing web-based technology in previous research is usually short, most studies falling between four to ten weeks (e.g. Chiu, Liou \& Yeh, 2007; Köroğlu \& Çakır, 2017; Satar \& Ozdener, 2008; Tazijan, Baharom \& Shaari, 2016). Moreover, although it is tempting to conclude in a straightforward manner that the application of a certain type of technology leads to the improvement in L2 oral performance, researchers should, however, take into consideration potential confounding factors, e.g. prior oral proficiency and technology usage experience. Sound statistical analysis should be performed to strengthen the credibility of research findings in WBLL studies. Low significance level, for example, $p=0.046$ in Baradaran and Khalili's (2009) would necessitate further investigation before any strong claim can be made. Interpreting a causal relationship between technology use and oral performance based on bivariate correlations only (e.g. Hwang et al, 2016) may not prove to be a convincing argument.

In summary, an increasing number of empirical studies have consistently confirmed the advantages of applying web-based language learning to enhance L2 learners' oral proficiency. Nevertheless, further research is guaranteed to explore new Web 2.0 tools used in different educational contexts. Sound experimental research design, controlling for potential confounding factors, would provide more persuasive evidence arguing the implementation of WBLL in formal language education.

\section{CONCLUSION}

Given technology rapidly infiltrating into L2 language classrooms, the current article aimed to review empirical studies employing web-based technology to assist L2 learners' speaking acquisition. Findings in this review were expected to inform its readers of an overview of how web-based resources had been utilized in foreign language education and research. 
After reviewing 31 empirical studies, it is safe to assert webbased language learning generally has a positive impact on learners' L2 speaking proficiency as well as on their affective factors. Teachers should play an active role in providing feedback and monitoring language learners' L2 oral development in web-based language learning environment. As Web 2.0 technology will continue to develop, more rigorous research is warranted to address the educational affordances of more advanced web-based platforms in diverse language education contexts.

\section{REFERENCES}

Abrams, Z. I. (2003). The effect of synchronous and asynchronous CMC on oral performance in German. The Modern Language Journal, 87(2), 157-167.

Al Hosni, S. (2014). Speaking difficulties encountered by young EFL learners. International Journal on Studies in English Language and Literature (IJSELL), 2(6), 22-30.

Appel, C., \& Borges, F. (2012). Task Design for L2 Oral Practice in Audioblogs. European Association for Computer-Assisted Language Learning (EUROCALL). Retrieved from https://files.eric.ed.gov/fulltext/ED544443. pdf

Baniabdelrahman, A. A. (2013). Effect of using Internet tools on enhancing EFL students' speaking skill. Journal of Contemporary Research, 3(6), 79-87.

Baradaran, A., \& Khalili, A. (2009). The impact of online chatting on EFL learners' oral fluency. JELS, 1(1), 63-77.

Blake, C. (2009). Potential of text-based internet chats for improving oral fluency in a second language. The Modern Language Journal, 93(2), 227-240.

Candarli, D., \& Yuksel, H. G. (2012). Students' perceptions of video-conferencing in the classrooms in higher education. Procedia-Social and Behavioral Sciences, 47 357-361.

Chiu, T. L., Liou, H. C., \& Yeh, Y. (2007). A study of webbased oral activities enhanced by automatic speech recognition for EFL college learning. Computer Assisted Language Learning, 20(3), 209-233.

Combe, C., \& Codreanu, T. (2016). Vlogging: a new channel for language learning and intercultural exchanges. In S. Papadima-Sophocleous, L. Bradley \& S. Thouësny (Eds), CALL communities and culture - short papers from EUROCALL 2016 (pp. 119-124). Research-publishing.net. https://doi.org/10.14705/rpnet.2016.eurocall2016.548.

Dailey, A. (2010). Difficulties implementing CLT in South Korea: Mismatch between the language policy and what is taking place in the classroom. Retrieved from https://www.birmingham.ac.uk/Documents/college-artslaw/cels/essays/sociolinguistics/ADaileyDifficultiesImplementingCLTinSouthKorea2.pdf

Dias, R., \& Pimenta, S. M. D. O. (2015). Technologies, literacies in English oral communication and teacher education: an empirical study at the university level. Revista Brasileira de Linguística Aplicada, 15(3), 711-733.

Dugartsyrenova, V. A., \& Sardegna, V. G. (2017). Developing oral proficiency with VoiceThread: Learners' strate- gic uses and views. ReCALL, 29(1), 59-79.

Faizi, R. (2018). Teachers' perceptions towards using Web 2.0 in language learning and teaching. Education and Information Technologies, 23(3), 1219-1230.

Ghoneim, N. M. M. \& Elghotmy, H. E. A. (2016). Using Voice Thread to Develop Pre-Service Teachers' Speaking Skills. International Journal of English Language Teaching, 4(6), 13-31.

Hsu, H. C. (2016). Voice blogging and L2 speaking performance. Computer Assisted Language Learning, 29(5), 968-983.

Huang, H. C. (2015a). From web-based readers to voice bloggers: EFL learners' perspectives. Computer Assisted Language Learning, 28(2), 145-170.

Huang, H. C. (2015b). The Effects of Video Projects on EFL Learners' Language Learning and Motivation: An Evaluative Study. International Journal of Computer-Assisted Language Learning and Teaching (IJCALLT), 5(1), 53-70.

Hung, S. T. A., \& Huang, H. T. D. (2015). Video blogging and English presentation performance: A pilot study. Psychological reports, 117(2), 614-630.

Hwang, W. Y., Shadiev, R., Hsu, J. L., Huang, Y. M., Hsu, G. L., \& Lin, Y. C. (2016). Effects of storytelling to facilitate EFL speaking using Web-based multimedia system. Computer Assisted Language Learning, 29(2), 215-241.

Kasuya, M. (2008). Classroom interaction affected by power distance. Language Teaching Methodology and Classroom Research and Research Methods. Retrieved from https://www.birmingham.ac.uk/Documents/college-artslaw/cels/essays/languageteaching/LanguageTeachingMethodologyMichikoKasuya.pdf

Köroğlu, Z. Ç., \& Çakır, A. (2017). Implementation of flipped instruction in language classrooms: An alternative way to develop speaking skills of pre-service English language teachers. International Journal of Education and Development using Information and Communication Technology, 13(2), 42-55.

Lai, C., \& Gu, M. (2011). Self-regulated out-of-class language learning with technology. Computer assisted language learning, 24(4), 317-335.

Li, S., \& Suwanthep, J. (2017). Integration of Flipped Classroom Model for EFL Speaking. International Journal of Learning and Teaching, 3(2), 118-123.

Li, Y., Gao, Y., \& Zhang, D. (2016). To Speak Like a TED Speaker--A Case Study of TED Motivated English Public Speaking Study in EFL Teaching. Higher Education Studies, 6(1), 53-59.

Lin, W-C., Shie, J-S, \& Holmes, P. (2017). Enhancing intercultural communicative competence through online foreign language exchange: Taiwanese students' experiences. Asian Journal of Applied Linguistic, 4(1), 73-88.

Long, M. H. 1996: The role of the linguistic environment in second language acquisition. In W. R. Ritchie and T. J. Bhatia (eds), Handbook of Second Language Acquisition. San Diego: Academic Press.

Luo, T. (2013). Web 2.0 for language learning: Benefits and challenges for educators. International Journal of Computer-Assisted Language Learning and Teaching, 3(3). 
Peyghambarian, F., Ashraf, H., \& Fatemi, M. A. (2014). The Effect of "GO ENGLISH. ME"A Virtual Learning Website on Lower Intermediate Iranian EFL Learners Speaking Ability. Advances in Language and Literary Studies, 5(6), 234-238.

Qarajeh, M., \& Abdolmanafi-Rokni, S. J. (2015). The impact of social networking on the oral performance of EFL learners. Advances in Language and Literary Studies, 6(2), 51-56.

Razagifard, P. (2013). The impact of text-based CMC on improving L2 oral fluency. Journal of Computer Assisted Learning, 29(3), 270-279.

Saito, K., \& Akiyama, Y. (2017). Video-Based Interaction, Negotiation for Comprehensibility, and Second Language Speech Learning: A Longitudinal Study. Language Learning, 67(1), 43-74.

Satar, H., \& Özdener, N. (2008). The effects of synchronous $\mathrm{CMC}$ on speaking proficiency and anxiety: Text versus voice chat. The Modern Language Journal, 92(4), 595613.

Shih, R. C. (2010). Blended learning using video-based blogs: Public speaking for English as a second languagestudents. Australasian Journal of Educational Technology, 26(6).

Sun, Y. C., \& Yang, F. Y. (2015). I help, therefore, I learn: service learning on Web 2.0 in an EFL speaking class. Computer Assisted Language Learning, 28(3), 202-219.

Sykes, J. M. (2005). Synchronous CMC and pragmatic development: Effects of oral and written chat. CALICO journal, 399-431

Tazijan, F. N., Baharom, S. S., \& Shaari, A. H. (2016). Building Communication Skills through Flipped Classroom. Proceedings of ISELT FBS Universitas Negeri Padang, 4(1), 289-295.

Ur, P. (1996). A course in language teaching. Cambridge: Cambridge University Press.

Vásquez, G. C., \& Arciniegas, L. P. (2017). A Webquest tool to develop communicative competence in EFL students with an A2 proficiency level. Zona Próxima, 26.

Vygotsky, L. S. (1978). Mind in society. The development of higher psychological processes (M. Cole, V. John-Steiner, S. Scribner, \& E. Souberman, Eds.). Cambridge, MA: Harvard University Press.

Wang, Y., \& Chen, N. S. (2007). Online synchronous language learning: SLMS over the Internet. Innovate: Journal of Online Education, 3(3).

Wei, J. (2014). A study via interviews of the Chinese Bouyei college learners' EFL classroom anxiety arousals. Journal of Language Teaching and Research, 5(2), 419-428.

Yusof, N. A., \& Saadon, N. (2012). The Effects of Web-based Language Learning on University Students' Grammar Proficiency. Procedia-Social and Behavioral Sciences, 67, 402-408.

Zhang, S. (2009). The role of input, interaction, and output in the development of oral fluency. English Language Teaching, 2(4),91-100. 